\title{
Religiosidade/espiritualidade na educação e na saúde: ensino e extensão
}

\author{
Religiousness/spirituality in education and \\ health: teaching and extension's action
}

\section{Luciana Fernandes Marques*}

Universidade Federal do Rio Grande do Sul, Porto Alegre, Rio Grande do Sul

\section{Resumo}

Como professora e pesquisadora tenho investigado o tema da Religiosidade/ Espiritualidade (R/E) desde 1992, quando iniciei meu mestrado sobre Práticas Alternativas em Psicologia. De lá para cá houve um incremento substancial na produção acadêmica e já há um vasto campo de estudos na Psicologia e em outras disciplinas afins. Embora as várias áreas de atuação possam incorporar intervenções na dimensão religiosa/espiritual, parece que é na Psicologia que esse tema pode melhor ser aprofundado, conhecendo as percepções, relatos, sentidos e significados atribuídos

\footnotetext{
LFM: Doutora em Psicologia, e-mail: luciana.marques@ufrgs.br
} 
pelas pessoas e a influência disso no comportamento. Este trabalho apresenta atividades de pesquisa, ensino e extensão que pretendem oferecer, aos campos da saúde e da educação, as contribuições da Psicologia da Religião e da Espiritualidade, informando sobre conceitos e teorias, apresentando metodologias de intervenção e sensibilizando estudantes e profissionais para a própria R/E, seja como forma de autocuidado, seja como desenvolvimento do Ser e autoconhecimento.

Palavras-chave: Psicologia e religião. Espiritualidade. Saúde. Educação.

\section{Abstract}

As a teacher and researcher, I have investigated the subject of religiousness/spirituality since 1992, when I started my Masters on Practices Alternatives in Psychology. Since then there has been a substantial increase in academic production and there is already a wide range of studies in psychology and other related disciplines. Although the various areas of activity can incorporate interventions in religious/spiritual dimension, it seems that is in the psychology that this issue can best be thorough, knowing the perceptions, reports, senses and meanings for people and the influence in their behavior. This paper presents research, education and extension that claim to offer to the fields of health and education, the contributions of Psychology of Religion and Spirituality, reporting on concepts and theories, with intervention methodologies and raising awareness of their own religiosity/spirituality as a form of self-care, either as development of Being and self-knowledge.

Keywords: Psychology and religion. Spirituality. Health. Education.

\section{Introdução}

Como professora e pesquisadora com formação de graduação e pós-graduação na Psicologia (Mestrado, Doutorado e dois Pós-Doutorados) e aplicando esse conhecimento na Educação (Faculdade de Educação, UFRGS) e na Saúde (Professora do Programa de Pós-Graduação Ensino na Saúde, Faculdade de Medicina, UFRGS), tenho investigado o tema da religiosidade/espiritualidade (R/E) desde 1992, quando iniciei meu 
mestrado sobre Práticas Alternativas em Psicologia. Naquela época, quase não existiam referências científicas em português que subsidiassem uma produção intelectual sobre o tema da religiosidade e da espiritualidade na Psicologia. De lá para cá, houve um incremento substancial na produção acadêmica, e já há um vasto campo de estudos na Psicologia e em outras disciplinas afins, inclusive pela visibilidade da produção alcançada pelo advento da World Wide Web.

A Psicologia da Religião e da Espiritualidade (PRE) tem estudado as dimensões psicológicas da religiosidade e da espiritualidade, em sua variedade de manifestações no comportamento humano. Nesse percurso, tem se voltado para a descrição e a classificação psicológica da realidade subjetiva da "religião" e para a aplicação desse conhecimento numa melhor compreensão de fenômenos típicos da atualidade (UTSCH, 2014), como o fanatismo religioso, a laicidade, o diálogo e a tolerância inter-religiosa, dentre outros. A Psicologia da Religião pode também contribuir para uma melhor compreensão de fenômenos típicos da atualidade, como o diálogo entre as culturas e as religiões e o crescente fundamentalismo (UTSCH et al., 1999).

No Brasil, há muito tempo, contamos com cientistas sociais e psicólogos sensíveis à necessidade de se levar a sério o estudo da religião (VALLE, 2012). Já é bastante conhecida sua influência na cultura, na vida em sociedade e suas implicações para a saúde e a qualidade de vida. A religiosidade, a espiritualidade, a conversão religiosa e os estados religiosos anômalos são parte da cultura e estão presentes na vida do povo brasileiro, especialmente entre as pessoas de origem afro, indígena e europeia portuguesa (BELZEN, 2010), sendo esses também temas e questões da competência e interesse da PRE.

Embora já tenha mais de um século de existência, esse campo de estudos não se faz presente na maioria dos cursos de graduação em Psicologia no Brasil. Algumas pesquisas têm confirmado o que se observa na prática, de que o tema é inexplorado na graduação em Psicologia (ANGERAMI-CAMON, 2008; CAVALHEIR; FALCKE, 2014). Poucos psicólogos se formam tendo conhecido a PRE e suas aplicações e, quando o fazem, é a partir de atividades extracurriculares ou disciplinas eletivas. Outra forma dos estudantes de psicologia conhecerem os temas da PRE 
é por meio da participação em grupos de estudos e em pesquisas sobre o tema. Entretanto, essa ausência no currículo da Psicologia não deve ser vista como um sinal de que a $\mathrm{R} / \mathrm{E}$ é uma dimensão menor na vida das pessoas, especialmente em se tratando de um povo religioso como o Brasil (MARTINS, 2012). O mais provável é que outros temas sejam mais valorizados, especialmente os temas tidos como essenciais no currículo mínimo na formação do psicólogo e que não possuem, necessariamente, interfaces com o tema da R/E. Pesquisas com estudantes de psicologia mostram o impacto na formação de teorias psicológicas que tendem a "patologizar" a religiosidade, de modo que muitos deles revelam sentimentos de despreparo e insegurança para lidar com as questões religiosas na sua vida profissional (FREITAS, 2014).

A PRE possui amplo arcabouço conceitual o qual pode ser aplicado em outros campos que não apenas na Psicologia. Inclusive muitos dos conceitos de religiosidade e de espiritualidade provêm de outras disciplinas. A partir da riqueza de conceitos provindos de diversas áreas e concepções, e efetuando recortes específicos, pode-se observar o potencial do tema para ser explorado em vários públicos, contextos e disciplinas. Igualmente, não parece imprescindível e nem apropriado a escolha de apenas um conceito a ser adotado em todos os contextos, já que grande parte da vivência religiosa e espiritual das pessoas provêm da cultura e de fases específicas da vida, mudando com o passar do tempo. Parte desses conceitos pode (e talvez deva) ser discutido com o público a quem se destina o trabalho, garantindo que os conceitos adotados façam referência às percepções e às formas particulares das pessoas e grupos viverem sua espiritualidade. Tais variedades conceptuais também indicam o quanto esse processo pode sofrer influências culturais variadas, como aquelas oriundas da religiosidade do lugar, das biografias individuais, da faixa etária predominante, e de outros inúmeros fatores.

Avaliando-se a produção acadêmica sobre esse tema, percebe-se a necessidade de uma perspectiva interdisciplinar para enfrentar os desafios e demandas do mundo contemporâneo em que, paradoxalmente, ao lado da secularização, assistimos a uma busca intensa de desenvolvimento da R/E (OLIVEIRA; GOLDIM, 2013). Na realidade brasileira, tanto os profissionais quanto a população em geral, parecem sensíveis ao tema. 
Dessa forma, junto ao estudo da religiosidade devem ser desenvolvidos estudos interdisciplinares e questões relacionadas às crenças religiosas e populares, os quais, por sua vez, deveriam ser inseridos nos currículos, em diálogo com a racionalidade científica, de modo que os futuros profissionais fossem mais bem preparados para lidar de modo ético e consistente com essa dimensão (FREITAS, 2014).

Na Educação, por exemplo, nos cursos de Pedagogia e licenciaturas, há oferecimento da disciplina obrigatória Psicologia da Educação. Muitos estudos psicológicos são aplicados aos campos educacionais, como a Teoria do Desenvolvimento Infantil de Jean Piaget (MACEDO, 2013), a Educação Centrada no Aluno de Carl Rogers (ROGERS; MACHADO; ANDRADE, 1972) e a Psicanálise de Freud (KUPFER, 1989). A PRE pode contribuir na problematização do ensino religioso laico e participar da formação continuada de professores para essa área. Também no ensino de crianças e jovens é pertinente mobilizar profissionais e estudantes para uma formação ética, moral e estímulo do desenvolvimento espiritual, numa abordagem mais integral ao humano.

Igualmente, o campo da saúde pública tem muito a se beneficiar com as produções da Psicologia e, em especial as que se voltam para temas de $\mathrm{R} / \mathrm{E}$ relacionadas diretamente com tópicos de bioética e com as práticas de saúde integrativas e complementares (CARDOSO et al., 2012). Alguns profissionais da saúde estão atentos aos avanços teóricos em torno do tema da espiritualidade, tomando para si a questão do cuidado espiritual (GOMES, 2013). Na medicina, em geral, são muitas as publicações em português sobre os temas da religiosidade e da espiritualidade (EDUARDA et al., 2014; LUCCHETTI; LUCCHETTI, AVEZUM, 2011). Embora as várias áreas de atuação possam incorporar intervenções na dimensão religiosa/ espiritual, parece que é na Psicologia que esse tema pode melhor ser aprofundado, conhecendo as percepções, relatos, sentidos e significados atribuídos pelas pessoas e a influência disso no comportamento.

Este trabalho apresenta atividades de pesquisa, ensino e extensão que pretendem oferecer, aos campos da saúde e da educação, as contribuições da PRE, informando sobre conceitos e teorias, apresentando metodologias de intervenção e sensibilizando estudantes e profissionais para a própria $\mathrm{R} / \mathrm{E}$, seja como forma de autocuidado, seja como desenvolvimento 
do Ser e autoconhecimento. Tanto na formação de professores, quanto na dos profissionais de saúde, a instrumentalização para lidar com a R/E do seu público e pensar questões contemporâneas globais são demandas atuais. As discussões atuais em torno da laicidade e dos direitos humanos tem levado os psicólogos a se questionarem sobre suas (pro)posições ao lidar com a R/E, já que sua invisibilidade fere o direito fundamental do cidadão de receber assistência espiritual. Por outro lado, os profissionais da saúde e da educação que lidam cotidianamente com pessoas e seus adoecimentos e florescimentos, precisam de recursos internos para que seu trabalho não se torne um fardo. Consideramos que a sensibilização de estudantes e profissionais para dimensão da R/E, de acordo com as inclinações pessoais de cada um, pode prover uma centralidade e equilíbrio em meio aos desafios diários encontrados. Dessa forma, a R/E pode ser apresentada como um tema de autocuidado, indo desde abordagens mais teístas e religiosas até outras mais existenciais, filosóficas e laicas, conforme o público a que é apresentado.

\section{Meditando na escola}

Uma das atividades de pesquisa desenvolvidas no campo da Educação, e que contou com a presença de temas da PRE, foi um estudo teórico sobre meditação com crianças no ambiente escolar, no ensino infantil, sob uma visão de educação integral e holística, a partir da busca teórica de temas da espiritualidade na infância. O objetivo do estudo foi fazer um levantamento de fundamentos teóricos, a fim de refletir de que maneira a meditação, enquanto prática laica e do âmbito da psicologia, pode beneficiar o desenvolvimento da criança na sua integralidade, estimulando a aprendizagem intelectual, moral, emocional e física, de forma integrada. Foram encontrados subsídios sobre a meditação e identificados quais os tipos de práticas que podem ser benéficas para as crianças. As primeiras reflexões giraram em torno da importância do brincar educativo, que se originou na antiguidade greco-romana, ligada à ideia de relaxamento necessário às atividades que exigem esforço físico e intelectual (UJIIE, 2007, p. 02). 
Ao longo do estudo, a meditação foi relacionada ao desenvolvimento das dimensões cognitiva, afetiva e psicológica que buscam desconstruir a visão do senso comum de que a mente e o corpo estão separados. Especialmente no trabalho com crianças, essa visão deveria ser reforçada para que, ao longo desse período crucial do desenvolvimento humano, a criança experimentasse a si mesma como um todo orgânico indiviso e, se possível, como parte indissociável do seu contexto e do ambiente. A partir de um levantamento realizado, também foram indicadas formas de como essas práticas podem ser abordadas no dia-a-dia da educação infantil que visam o desenvolvimento positivo da criança (SHAPIRO; SCHWARTZ; SANTERRE, 2005).

Além da meditação, foram encontradas outras formas de abordar o ser integral da criança como os movimentos corporais, a dança, a dramatização e os exercícios que estimulam a concentração, permitindo o relaxamento e o estímulo da relação corpo-mente (YUS, 2002). Nesse sentido, a PRE pode contribuir investigando os benefícios dessas práticas no desenvolvimento infantil e gerando implicações nos currículos escolares, prevendo espaço e tempo para atividades lúdico-espirituais em que a meditação é inserida através do brincar na rotina da Educação Infantil. Por exemplo, antes ou depois do intervalo podem ser feitas pequenas paradas para tomar consciência da respiração, ouvir os sons ao redor, relaxar e perceber o ambiente e o corpo. Apesar de muitas escolas reproduzirem um sistema fragmentado em seus saberes, é possível que novas maneiras de articulação sejam inseridas na rotina escolar, de modo que as crianças integrem as vivências e os diversos saberes de forma significativa a partir da própria experiência. Uma das formas de fazer isso é através do silêncio e da presença mental, na experiência do momento presente por via da meditação.

O que parece evidente nos trabalhos encontrados é a defesa da ideia de uma educação focada no aluno. A educação holística almeja desenvolver, na sala de aula, um ambiente integrador que permita expandir outros aspectos do aluno, como o seu lado emocional, artístico, sensível ou ainda espiritual (YUS 2002). Para isso, requer-se um conhecimento de como essas práticas integrativas atuam na experiência global da criança e do jovem e como podem promover bem-estar e desenvolvimento positivo. 
A educação, nessa visão, não se centra na determinação de quais fatos ou habilidades os adultos deveriam ensinar às crianças, mas na criação de uma comunidade de aprendizagem que estimule o crescimento do envolvimento criativo e interrogativo da pessoa com o mundo. Nessa visão, os alunos não são passivos e repetidores do que recebem, mas são investigativos e protagonistas do seu processo de aprendizagem individual e coletivo. A educação holística, dessa forma, é nutridora de pessoas saudáveis, completas e curiosas que podem aprender qualquer coisa que precisem e em qualquer contexto (YUS, 2002, p. 17).

De uma maneira saudável, seria uma nutrição intelectual, possibilitando que o aluno crie suas estratégias ao perceber e compreender os diversos contextos que determinam e dão significado para a vida. Essa proposta também busca reconhecer e valorizar o potencial e a habilidade de cada um para que a autoestima também seja trabalhada contribuindo para um maior equilíbrio entre o conhecimento e a imaginação. A autoestima se fortalece porque o aluno é cocriador no processo de aprender e não apenas assimila e repete o conhecimento tido como "certo". Os papéis de professor e aluno são repensados dentro de uma visão de desenvolvimento humano e não apenas numa perspectiva da aprendizagem escolar de conteúdos. O que seria a inclusão de uma simples técnica, como a da meditação no espaço escolar, pode passar a ser a reformulação da visão de ser humano, de aprendizagem e do propósito da educação.

\section{Rede de Professores: espiritualidade e resgate de saberes integrais}

Em 2015 ocorreu a segunda edição de uma ação de extensão voltada para professores, realizada totalmente em EAD também pela universidade citada na introdução. A "Rede de professores: espiritualidade e resgate de saberes integrais" foi desenvolvida em nove módulos e 150 horas. Uma das riquezas dessa modalidade é reunir num mesmo espaço (virtual) pessoas de variados contextos em que se pode compartilhar experiências, influenciar os outros, bem como ser influenciado, além de compartilhar valores e práticas. Por meio dos ambientes virtuais de aprendizagem emergem novas alternativas de produzir, compartilhar e disponibilizar 
conhecimento. A ideia geral do projeto foi disponibilizar materiais voltados para o desenvolvimento da espiritualidade na educação, bem como a formação desses professores. O fato de encontrarmos subsídios no campo da PRE nos dá respaldo para manter uma discussão científica.

Como professores, estamos expostos à diversidade religiosa dos nossos alunos bem como ao princípio da laicidade do país. Por outro lado, não há uma licenciatura específica que forme professores para o Ensino Religioso, uma disciplina obrigatória ofertada nas escolas. Muitas são as queixas de que os alunos têm conteúdos "catequísticos" de outras religiões que não a que seguem em casa. O espaço dessa disciplina fica pouco explorado quando é urgente a necessidade de transformar a cultura rumo a pessoas mais compassivas, generosas, pacientes, atentas a si, aos outros, à natureza e ao ambiente independente das (ou de comum acordo com as) diferentes religiosidades. Dessa forma, justificamos a importância do professor estar sensível à sua dimensão espiritual e conhecer teorias e metodologias de suporte para uma prática docente, incluindo o desenvolvimento da espiritualidade e os saberes integrais (aqui entendidos como valores universais).

Nesta segunda edição ficou evidente a ausência do tema da R/E na formação de graduação dos profissionais da Educação. Após o contato direto com os professores na primeira edição, pudemos aprimorar a visão da sua realidade e do déficit de conhecimento nessa área em que os professores não estão preparados para abordar a $\mathrm{R} / \mathrm{E}$ dos seus alunos, tanto de forma geral quanto mais especificamente no ensino religioso.

\section{Práticas contemplativas no SUS}

No campo da saúde pública, orientei uma dissertação de mestrado sobre o uso das práticas contemplativas em pacientes com dor crônica do SUS. O trabalho evidenciou que as Políticas Nacionais de Atenção à Saúde, propostas nos últimos anos, visam garantir a execução de estratégicas educativas que promovam o cuidado integral dos usuários do Sistema Único de Saúde (SUS). Assim, encontramos a Portaria no 971 do Ministério da Saúde, de 2006, que garante a integralidade nas ações em saúde e institui 
a Política Nacional de Práticas Integrativas e Complementares (PNPIC) no SUS, que faculta novas abordagens de intervenção (BRASIL, MINISTÉRIO DA SAÚDE. GABINETE DO MINISTRO, 2006).

O objetivo do trabalho foi investigar os benefícios do uso da prática contemplativa (que seria uma meditação ampliada para atividades em movimento) em grupos de usuários com dor crônica para, posteriormente, propor sua integração no serviço de atenção à saúde do SUS. O estudo consistiu numa intervenção de 90 minutos, na qual foi utilizada a prática contemplativa durante 13 semanas com oito participantes que apresentavam dores crônicas há mais de um ano, oriundos dos grupos de atividades físicas existentes no Centro de Reabilitação/Gerência Glória Cruzeiro Cristal (Porto Alegre, RS). O critério norteador de inclusão na pesquisa-intervenção foi ter dor crônica por um período superior a um ano e possuir mais de 18 anos. Como se tratava de uma prática complementar, não houve modificações no esquema medicamentoso de controle da dor dos usuários.

Durante a intervenção, foram trabalhados alguns dos princípios básicos do mindfulness como: reconhecer a tendência para estarmos em "piloto automático", assumir um compromisso no sentido de aprender a sair desse estado e de nos tornarmos mais conscientes e presentes com a experiência, fomentar uma postura de aceitação e gentileza para consigo mesmo e em relação aos outros, procurar intencionalmente focalizar a atenção no corpo e ver o quão difícil/fácil isso pode ser (SMITH, 1975). Também foi orientada a escuta de um áudio com uma gravação de 10 minutos sobre as diferentes fases do escaneamento corporal. Além da intervenção propriamente dita, os participantes responderam a um questionário de dados biossociodemográficos com questões de identificação. Também foi aplicada a Escala Visual Analógica de Intensidade de Dor de Cores e Faces, pela qual o usuário localiza sua dor em uma escala de 0 a 10, correspondendo 0 à ausência total de dor e 10, à dor máxima. Na sequência, foi aplicada a Escala de Atenção e Consciência Plena (BROWN; RYAN, 2003), fundamentada na regulação atencional e que inclui 15 perguntas, com opções de resposta numa escala Likert de 1 a 6 . Neste instrumento, os participantes indicam a frequência com que estiveram atentos às experiências do cotidiano. 
Os resultados indicaram que a Prática Contemplativa possibilitou um melhor gerenciamento da dor crônica e a melhora da atenção plena nas atividades do cotidiano, apresentando-se como uma ferramenta pedagógica para promover o autocuidado com vistas à educação do Ser. Ao longo da pesquisa-intervenção constatamos dois sentidos atribuídos à saúde pelos usuários a partir da prática contemplativa desenvolvida: (1) saúde é autoconhecimento e autocuidado e (2) saúde é relação social e afetiva. A prática contemplativa utilizada no Centro de Reabilitação não se propõe a curar pacientes, mas sim a ajudá-los a resgatar algo significativo em suas vidas que, em algum momento, pode ter sido perdido: resgatar o próprio ser, conhecer o corpo, senti-lo e ouvi-lo a fim de que possa adquirir autonomia e incentivo para o autocuidado. Nesse sentido, aspectos existenciais da espiritualidade foram trabalhados como o sentido atribuído à experiência e à transcendência, para além da mera fuga da dor. Vimos, também, que os temas de PRE podem contribuir em grande medida no trabalho em saúde pública e na visão da integralidade do usuário do sistema de saúde.

\section{R/E em profissionais de saúde}

Outro estudo realizado foi uma investigação quantitativa sobre a R/E nos profissionais de saúde no contexto hospitalar da cidade de Porto Alegre e região metropolitana. O contexto hospitalar é um espaço em que a valorização do saber científico é bastante evidente. Muitas vezes isso ocorre em detrimento de outros saberes, como os relacionados à espiritualidade, que parece ser um tópico pouco abordado entre profissionais da saúde. É preciso retomá-la se buscamos uma visão integral do sujeito que acolha seus diferentes aspectos. Isto se torna ainda mais importante se considerarmos que uma das dificuldades encontradas pelos profissionais da saúde está em como auxiliar os pacientes na busca por sentido e aceitação em meio ao sofrimento, a doenças crônicas e as perdas, sendo que, para muitas pessoas, a base do sentido e do propósito se relaciona diretamente com a religião e/ou a espiritualidade (PUCHALSKI, 2001). Aceitar a influência da R/E na saúde significa partir de uma visão integral, 
abordando as diferentes dimensões do sujeito e superando o modelo biomédico responsável por um atendimento fragmentado (ALVES; JUNGES; LÓPEZ, 2010).

O objetivo desse estudo foi verificar o modo como a dimensão da $\mathrm{R} / \mathrm{E}$ é vista e encaminhada na prática dos profissionais da área da saúde que trabalham em hospitais. A pesquisa foi realizada com 174 profissionais de saúde de variadas instituições de saúde pública. Os participantes responderam a um questionário com 35 questões em que constavam dados sociodemográficos e questões fechadas sobre a prática da R/E desses profissionais. O público foi de 143 mulheres e 31 homens, com idades entre 19 e 63 anos (média de 41,02 e DP de 10,79), de diferentes profissões da saúde. Sobre a afiliação religiosa, as respostas mais frequentes foram: espírita (21\%), católico não praticante (18,2\%), sem religião mas crente em Deus (14,2\%), afro-brasileiras (11,9\%) e católico praticante $(10,8 \%)$. Os dados apontam para a necessidade dos profissionais estarem mais capacitados para lidar com a demanda religiosa/espiritual dos pacientes. Eles demonstram interesse pelo tema e acreditam que é importante a relação entre $\mathrm{R} / \mathrm{E}$ e saúde. Também, chamam atenção para ausência desse tema na sua formação técnico-profissional e para a falta de espaços e estruturas institucionais que acolham essas demandas do usuário do sistema de saúde.

\section{Considerações finais}

A partir das atividades relatadas, encontramos um firme suporte para que a PRE colabore e tenha apresentada e reconhecida a sua produção para os campos da Educação e da Saúde Pública, assim como em outras áreas a fins como a Teologia, Ciências da Religião, Medicina, Psiquiatria, Antropologia, dentre outras, para que não esteja circunscrita ao campo da Psicologia como ciência e profissão. Da mesma forma, esse campo deve participar da formação na graduação de profissionais de saúde e de educação, relacionado aos temas específicos de cada profissão. Na educação continuada, seja em cursos de pós-graduação ou de extensão, também pode 
ser abordado, tanto em atividades presenciais quanto virtuais. Nessas atividades de ensino, observa-se que não apenas os conceitos teóricos devem ser informados, mas também deve haver uma problematização dos contextos de onde provém o público-alvo, para que assim, o tema da $R \backslash E$ esteja em consonância com as demandas presentes e visualizadas formas específicas de aplicação. Igualmente, pode-se observar o quanto a R/E é um tema de autocuidado e autoconhecimento na medida em que, tanto na área da educação quanto na da saúde, os profissionais lidam com pessoas e são desafiados diariamente. Nesse caso, a R/E pode ser um recurso de enfrentamento, mas também uma dimensão que explora os sentidos e propósitos de vida, estimulando o profissional a se reconectar consigo, com os outros e com o ambiente.

Outra reflexão a salientar, decorrente dos trabalhos acima apresentados, é a porosidade do campo da PRE. O tema da R/E é bastante amplo e, para uma abordagem mais complexa, pode ser investigado e abordado de formas interdisciplinares e até transdisciplinares (em diálogo com a filosofia, arte, saberes e tradições). O ponto de vista da PRE pode manter suas especificidades, mas dificilmente ficará isento de discutir implicações próprias de outros campos.

\section{Referências}

ALVES, J. S.; JUNGES, J. R.; LÓPEZ, L. C. A dimensão religiosa dos usuários na prática do atendimento à saúde: percepção dos profissionais da saúde. O Mundo da Saúde, São Paulo, v. 34, n. 4, p. 430-436, 2010.

ANGERAMI-CAMON, V. A. Religiosidade e psicologia: a contemporaneidade da fé religiosa nas lides acadêmicas. In: ANGERAMI, V. A. (Org.), Psicologia e religião. São Paulo: Cengage Learning, 2008. p. 1-42.

BELZEN, J. A. Para uma Psicologia Cultural da Religião. Princípios, Aproximações, Aplicações. São Paulo: Editora Ideias e Letras, 2010. 
BRASIL. MINISTÉRIO DA SAÚDE. GABINETE DO MINISTRO 2006. Portaria MS/ GM n 971, 3 de maio de 2006. Aprova a Política Nacional de Práticas Integrativas e Complementares (PNPIC) no Sistema único de Saúde. Diário Oficial da União, Brasília, ed. 84, p. 20-24, 4 de maio de 2006.

BROWN, C. A.; RYAN, R. M. The benefits of being present: Mindfulness and its role in psychological well-being. Journal of Personality and Social Psychology, v. 84, p. 822-848, 2003.

CARDOSO, T. B. et al. Perspectivas da Medicina Tradicional e das práticas contemplativas na faculdade de medicina de Botucatu, UNESP. Revista Brasileira de Medicina de Família e Comunidade, v. 7, n. 1, p. 68, 2012.

CAVALHEIRO, C. M. F.; FALCKE, D. Espiritualidade na formação acadêmica em psicologia no Rio Grande do Sul. Estud. psicol. (Campinas), v. 31, n. 1, p. 35-44, 2014.

EDUARDA, B. M. et al. Espiritualidade e Medicina: Interfaces e Diálogos. Blucher Medical Proceedings, v. 1, n. 2, p. 25-25, 2014.

FREITAS, M. H. Religiosidade e saúde: experiências dos pacientes e percepções dos profissionais. Revista Pistis Praxis, v. 6, n. 1, p. 89-105, 2014.

GOMES, A. M. T. A espiritualidade como um elemento do cuidado de enfermagem: aproximação e desafios. Revista Enfermagem UERJ, v. 20, n. 6, p. 699-700, 2013.

KUPFER, M. C. M. Freud e a educação: o mestre do impossível. São Paulo: Scipione, 1989.

LUCCHETTI, G.; LUCCHETTI, A. L. G.; AVEZUM JR, Á. Religiosidade, espiritualidade e doenças cardiovasculares. Rev Bras Cardiol, v. 24, n. 1, p. 55-57, 2011.

MACEDO, L. Para uma aplicação pedagógica da obra de Piaget: algumas considerações. Cadernos de Pesquisa, n. 61, p. 68-71, 2013.

MARTINS, A. R. Novo Mapa das Religiões no Brasil. Horizonte, v. 9, n. 23, p. 942945, 2012.

OLIVEIRA, J. B.; GONDIM, M. F. de. "Psicologia da religião no mundo ocidental contemporâneo: desafios da interdisciplinaridade" (Vol. I \& II). Rev. abordagem gestalt., Goiânia, v. 19, n. 2, dez. 2013. 
PUCHALSKI, C. M. The hole of spirituality in health care. BUMC Proceedings, v. 14, p. 352-357, 2001.

ROGERS, C. R.; DA MATA MACHADO, E. G. de; DE ANDRADE, M. P. Liberdade para aprender: uma visão de como a educação deve vir a ser. Belo Horizonte: Interlivros de Minas Gerais, 1972.

SHAPIRO, D. L.; SCHWARTZ, G. E.; SANTERRE, C. Meditation and positive psychology. In: SNYDER, C. R.; LOPEZ, S. J. Handbook of Positive Psychology. New York: Oxford USA Trade, p. 632-645, 2005.

SMITH, J. C. Meditation as psychotherapy: A review of the literature. Psychological Bulletin. v. 82, n. 4, p. 558-564, 1975.

UJIIE, N. T. Ação lúdica na Educação Infantil. Colloquium Humanarum, v. 4, n. 1, Jun. , p. 01-07, 2007.

UTSCH, M. Tarefas e limites da psicologia da religião: uma perspectiva dialogal/ Tasks and limits of psychology of religion: a dialogical perspective. Numen, v. 16, n. 2, 2014.

UTSCH, M. Millenniumsängste aus psychologischer Sicht. Materialdienst der EZW 61 n. 12, p. 319-330, 1999.

VALLE, E. Uma leitura brasileira de "Para uma Psicologia Cultural da Religião", de Jacob A. Belzen. Revista de Estudos da Religião (REVER). ISSN 1677-1222, v. 12, n. 1, p. 219-238, 2012.

YUS, R. Educação Integral uma educação holística para o século XXI. Trad. Daisy Vaz de Moraes. Porto Alegre: Artmed, 2002.

Recebido: 03/11/2016

Received: 11/03/2016

Aprovado: 18/03/2017

Approved: 03/18/2017 
